\title{
Cabaran Kontemporari di Era Globalisasi dalam Pengurusan Masyarakat oleh Pendakwah Selebriti Wanita di Malaysia
}

\author{
Fatimah Syarha Mohd Noordin \\ Universiti Malaya, fatimahsyarha7@gmail.com \\ Mohammed Yusuf \\ Universiti Malaya,my77@um.edu.my \\ Nur Shahidah Paad \\ Universiti Malaya, shaaz2301@um.edu.my \\ DOI: https://doi.org/10.22452/usuluddin.vol47no2.4
}

\begin{abstract}
Abstrak
Dunia hari ini menyaksikan globalisasi meninggalkan impak yang besar dalam kehidupan wanita. Globalisasi mencorakkan kehidupan serba kompleks dan mempunyai impak positif dan negatif. Bagi pendakwah selebriti wanita, globalisasi mempunyai cabaran tersendiri dalam mendepani pengurusan masyarakat. Metode kualitatif digunakan dalam kajian ini dengan pendekatan kajian kes dan menggunakan metod temu bual secara mendalam. Dari segi persampelan, informan yang dipilih adalah dua orang pendakwah selebriti wanita di Malaysia iaitu Isfadiah Mohamed Dasuki dan Norhafizah Musa. Kajian mendapati antara cabaran yang dihadapi oleh mereka adalah kekaburan (ambiguity), kerumitan (complexity), perubahan mendadak (volatility) dan ketidakpastian (uncertainty).
\end{abstract}

Kata kunci: pengurusan, globalisasi, cabaran pendakwah selebriti kontemporari

\section{The Contemporary Challenges of Public Management by Women Celebrity Preachers in Malaysia}

\begin{abstract}
Today's world sees globalization leaving a huge impact on women's lives. Globalization is shaping a complex life with positive and negative impacts. For female celebrity preachers, globalization has its own challenges when it comes to managing society. Qualitative methods were used in this study with a case study approach and in-depth interview method. In terms of sampling, the informants selected were two female celebrity preachers in Malaysia: Isfadiah Mohamed Dasuki and Norhafizah Musa. Studies have found that the challenges they face are ambiguity, complexity, complexity, volatility and uncertainty.
\end{abstract}

Keywords: management, globalization, contemporary challenges of celebrity preachers 


\section{Pendahuluan}

Pendakwah selebriti wanita yang menguruskan masyarakat sudah tentu mempunyai cabaran yang tersendiri. Perkataan selebriti merujuk Kamus Pelajar Edisi Kedua oleh Dewan Bahasa dan Pustaka bermaksud orang yang terkenal dan menjadi tumpuan ramai. ${ }^{1}$ Pendakwah selebriti wanita yang dimaksudkan dalam kajian ini ialah penceramah agama di kalangan wanita yang menjadi tumpuan ramai.

Populariti pendakwah selebriti wanita boleh menjadi agen perubahan ke arah mewujudkan masyarakat yang lebih adil dan pertengahan. Lebih-lebih lagi, kejadiannya sebagai wanita sering dikaitkan di serata dunia dengan nilai dari hati (heart-centred value) yang prihatin terhadap kesejahteraan keluarga, anak-anak, mahukan keamanan, pendidikan, nilai moral, keadilan serta risaukan peperangan, pencemaran dan penyakit. $^{2}$ Pendakwah selebriti wanita mempunyai peluang dan potensi yang sangat luas dalam menguruskan masyarakat untuk mengembangkan perkara yang baik dan bermanfaat.

Metode kualitatif dipilih dalam kajian ini dengan pendekatan kajian kes dan menggunakan metode temu bual secara mendalam. Dari segi persampelan, informan yang dipilih adalah dua orang pendakwah selebriti wanita di Malaysia iaitu Isfadiah Mohamed Dasuki dan Norhafizah Musa. Isfadiah Mohamed Dasuki merupakan graduan Universiti Islam Antarabangsa Malaysia (UIAM) pada tahun 1994 dengan Ijazah Sarjana Muda (Kepujian) dalam kursus Ilmu Wahyu serta minor dalam bidang Komunikasi. Beliau menyempurnakan Sarjana dalam bidang Psikologi di Universiti Kebangsaan Malaysia (UKM) pada tahun 1998. Kerjaya beliau sekarang adalah Felo Dakwah YADIM, Pengarah Akademi Keluarga Fitrah, Master Trainer Fitrah Guidance \& Consultancy dan Pengarah Eksekutif Labbaik Travel \& Tours. Manakala Norhafizah Musa dilahirkan di Kampung Kuala Jempol, Negeri Sembilan. Merupakan anak ke-5 daripada 6 orang adik beradik.

1 "Selebriti", laman sesawang Dewan Bahasa dan Pustaka, dicapai 17 April 2018, http://prpm.dbp.gov.my/Cari1?keyword=selebriti

2 (Kertas Kerja, International Conference on Women Security and Global Challenges, Wadah Pencerdasan Umat Malaysia (WADAH, ABIM), 4 Mei 2019). 
Beliau juga memegang Ijazah Kedoktoran dari Universiti Malaya selepas menamatkan penyelidikan di Jabatan Akidah Dan Pemikiran Islam, Akademi Pengajian Islam. Penglibatan beliau dalam bidang dakwah bermula sebaik sahaja beliau kembali dari pengajian di Jordan. Cuma pada waktu itu, beliau belum lagi terlibat di media elektronik. Kini, beliau aktif menerima jemputan di dalam dan luar negara.

Kajian ini memilih para pendakwah selebriti wanita yang mempunyai ribuan pengikut dan aktif dalam media massa sejak 2014-2019. Justifikasi diletakkan tempoh kerana dikhuatiri apabila tesis ini siap, mereka bukan lagi bergelar selebriti. Rajah berikut menunjukkan nama informan dan jumlah pengikut mereka di "Instagram":

Rajah 1: Paparan pengikut pendakwah selebriti wanita di akaun Instagram

\begin{tabular}{|c|c|}
\hline Pendakwah Selebriti & Pengikut \\
\hline Norhafizah Musa & 473,000 \\
\hline Isfadiah Mohamed Dasuki & 218,000 \\
\hline
\end{tabular}

\section{Cabaran Kontemporari di Era Globalisasi}

Dalam era kontemporari ini, ketika informasi datang dari langit tanpa sempadan sekaligus datang kemanfaatan dan kemaslahatan serta cabaran yang besar apabila dunia menuju ke arah pola simplikasi dan berasaskan materialisme. ${ }^{3}$ Secara ringkas, cabaran pengurusan masyarakat oleh pendakwah selebriti wanita merujuk kepada:

1. Perubahan Mendadak Dunia Globalisasi (Volatility).

2. Ketidakpastian Penerimaan atau Penentangan Dakwah oleh Pihak Sekeliling (Uncertainty).

3. Kerumitan Mengurus Pelbagai Ideologi Masyarakat (Complexity).

4. Kekaburan Antara Dakwah dan Profesion (Ambiguity).

Berikut adalah rajah yang menunjukkan cabaran-cabaran tersebut diikuti penjelasan lanjut.

3 (Kertas Kerja, International Conference on Women Security and Global Challenges, Wadah Pencerdasan Umat Malaysia (WADAH, ABIM), 4 Mei 2019). 


\section{Rajah 1: Cabaran-cabaran Pengurusan} Masyarakat oleh Pendakwah Selebriti Wanita
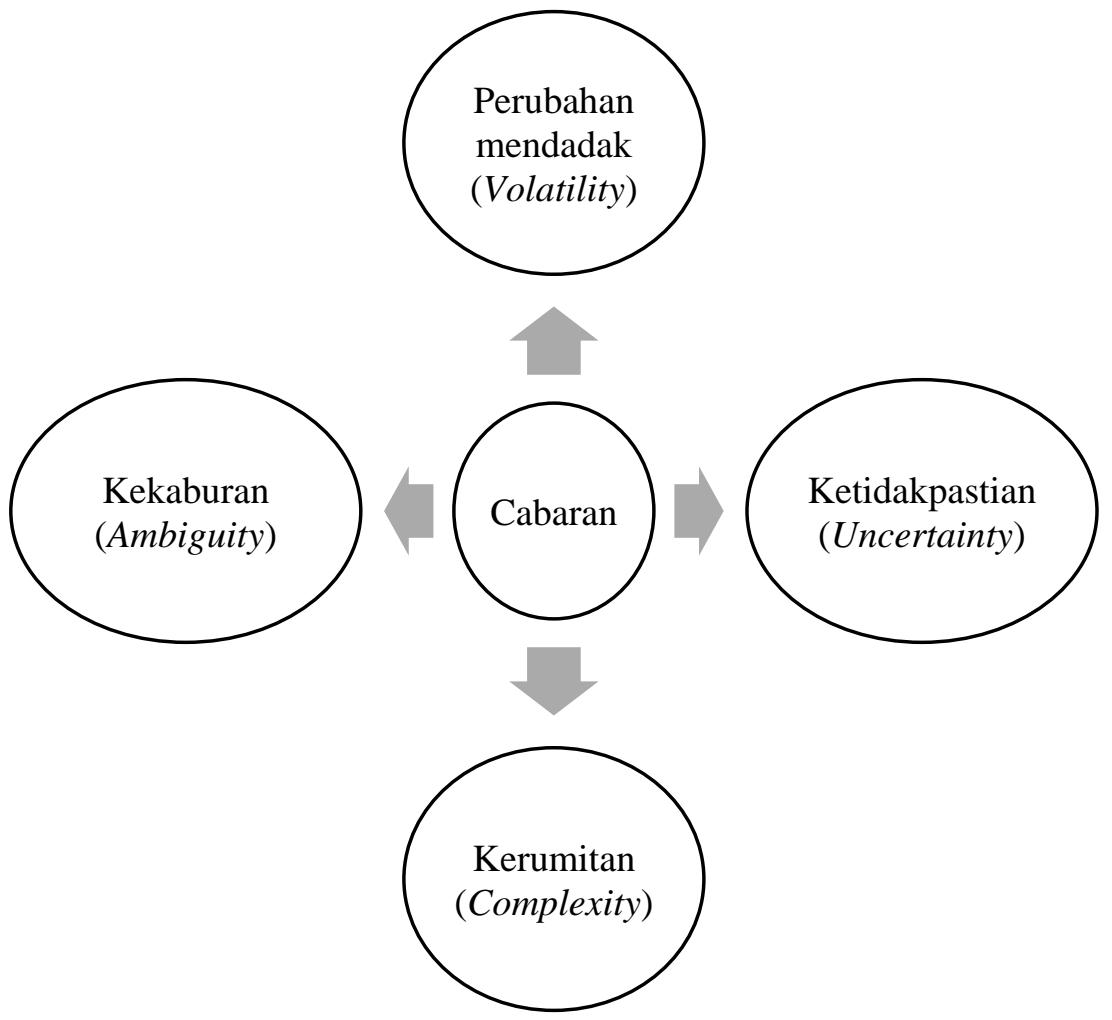

Sumber: International Conference On Women Security and Global Challenges ${ }^{4}$

\section{Perubahan Mendadak Dunia Globalisasi (Volatility)}

Globalisasi telah membawa perubahan besar secara mendadak dalam kehidupan manusia di seluruh dunia. Informasi yang terjadi di ceruk manapun sepantas kilat akan segera diketahui oleh masyarakat di negara-negara lain dan tiada halangan untuk

4 (Kertas Kerja, International Conference on Women Security and Global Challenges, Wadah Pencerdasan Umat Malaysia (WADAH, ABIM), 4 Mei 2019). 
masyarakat dunia saling berinteraksi dan saling mempengaruhi. ${ }^{5}$ Ditambah pula dengan cabaran media massa dalam penyebaran dan perluasan pengaruhnya. Tidak dinafikan, media massa mempunyai banyak kebaikan namun media massa juga telah menyebabkan gosip di sekitar hidup selebriti boleh diketahui setiap saat oleh mata publik dunia. ${ }^{6}$

Bagi pendakwah selebriti wanita, usaha memperkenalkan idea baru (khususnya memperkenalkan dakwah) bukanlah sesuatu yang mudah, apatah lagi di peringkat Negara. ${ }^{7}$ Ia memerlukan perancangan yang strategik, perlaksanaan yang rapi, iltizam politik yang bersungguh-sungguh, dan semangat kemanusiaan yang kukuh. ${ }^{8}$ Sering kali dalam usaha ini, komunikasi memainkan peranan yang signifikan. ${ }^{9}$ Komunikasi amat diperlukan untuk menyebarkan dakwah, jika komunikasi tidak dirancang dan dilaksanakan dengan baik, dakwah itu mungkin gagal diterima lalu tidak diadaptasi oleh khalayak sasaran yang terdiri daripada pelbagai peringkat pemikiran dan pendidikan. ${ }^{10}$

Menurut Rugayah Tibek, media boleh digunakan sebagai perantara penyampai dakwah baik media elektronik, cetak mahupun laman web. ${ }^{11}$ Seiring peningkatan masalah sosial, pendakwah selebriti wanita seharusnya mempelbagaikan kaedah dan metode dakwah untuk memaksimumkan matlamat dakwah lantaran media yang seharusnya berperanan menyampai

5 Cahyadi Takariawan, Tegar di Jalan Dakwah (Solo: PT Era Adicitra Intermedia, 2010), 99.

6 Cahyadi Takariawan, Tegar di Jalan Dakwah, 99.

7 Mohd Safar Hasim dan Zulkiple Abd. Ghani, Komunikasi dan Media dari Perspektif Islam: Konsep dan Amalan (Selangor: Penerbit Universiti Kebangsaan Malaysia, 2015), 227.

8 Mohd Safar Hasim dan Zulkiple Abd. Ghani, Komunikasi dan Media dari Perspektif Islam: Konsep dan Amalan, 227.

9 Mohd Safar Hasim dan Zulkiple Abd. Ghani, Komunikasi dan Media dari Perspektif Islam: Konsep dan Amalan, 227.

10 Mohd Safar Hasim dan Zulkiple Abd. Ghani, Komunikasi dan Media dari Perspektif Islam: Konsep dan Amalan, 227.

11 Siti Rugayah Tibek, Wanita, Dakwah dan Media, Wanita Islam Isu-isu dan Pemerkasaan Hak (Shah Alam: Persatuan Ulama Malaysia, 2011), 53. 
maklumat, namun dalam waktu yang sama juga menimbulkan permasalahan terutamanya kaum wanita. ${ }^{12}$

Justeru, benteng prinsip dan moral yang kukuh perlu dibina. Seterusnya, umat memerlukan tindakan berstruktur untuk mengembangkan alternatif hiburan dan informasi melalui stesyen televisyen dakwah ${ }^{13}$ yang mengambil Islam secara syumul.

Hasil kajian mendapati pendakwah selebriti Norhafizah Musa antara pendakwah yang menghadapi cabaran perubahan mendadak dunia globalisasi ini yang berkaitan dengan media. Norhafizah Musa berkata:

"Media yang selalunya mengejar 'rating' tinggi demi keuntungan kadang kala menuntut kreativiti dan penampilan yang berlebihan bagi seorang pendakwah selebriti wanita. Apabila berada di media elektronik ini, seseorang itu perlu ada prinsip yang jelas. Tidak dinafikan berada di bidang ini membuatkan kita diuji dengan tawaran atau projek yang kadang kala boleh menjejaskan prinsip terutama melibatkan perkara syubhah mahupun penampilan." 14

Beliau mengatasi cabaran ini dengan selalu meminta panduan daripada keluarga dan para alim ulama. ${ }^{15}$ Beliau berkata,

"Sebab itu kita perlu sentiasa mendapat panduan bagaimana untuk membawa diri dengan lebih baik kerana kita penceramah wanita". ${ }^{16}$

Hal ini diakui dan disaksikan oleh kakak beliau, Anisah Musa yang menambah:

"Ayah sentiasa menegur, jika ada tak kena, poin-poin tak kena, ayah akan 'call' dan sanggup datang ke KL. Tegur. Alhamdulllah, ayah kami masih bersama, dipanjangkan usia.

${ }^{12}$ Siti Rugayah Tibek, Wanita, Dakwah dan Media, Wanita Islam Isu-isu dan Pemerkasaan Hak, 53.

13 Siti Rugayah Tibek, Wanita, Dakwah dan Media, Wanita Islam Isu-isu dan Pemerkasaan Hak, 101.

14 Norhafizah Musa (pendakwah selebriti), dalam temubual dengan penulis, 15 Oktober 2018.

15 Nur Nadhratul Naemah binti Mohd Azhar (anak sulung pendakwah selebriti Norhafizah Musa), dalam temubual dengan penulis, 12 April 2019.

16 Nur Nadhratul Naemah binti Mohd Azhar (anak sulung pendakwah selebriti Norhafizah Musa), dalam temubual dengan penulis, 12 April 2019. 
Mereka adalah tulang belakang yang paling hebat. Alhamdulillah."17

\section{Ketidakpastian Penerimaan atau Penentangan Dakwah oleh Pihak Sekeliling (Uncertainty)}

Ketidakpastian penerimaan atau penentangan dakwah oleh pihak sekeliling berkait rapat dengan permainan dari sudut persepsi dan khabar angin yang ditelan bulat-bulat oleh yang tidak mempunyai maklumat yang secukupnya akan mengundang pelbagai petaka dan bahaya. ${ }^{18}$ Allah SWT berfirman :

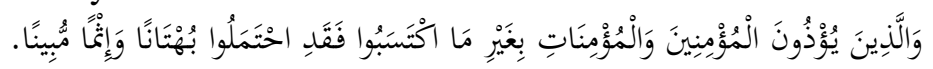

Al-Aḥzab 33:58

Terjemahan: Dan orang-orang yang mengganggu serta menyakiti orang-orang lelaki yang beriman dan orang-orang perempuan yang beriman dengan perkataan atau perbuatan yang tidak tepat dengan sesuatu kesalahan yang dilakukannya, maka sesungguhnya mereka telah memikul kesalahan menuduh secara dusta, dan berbuat dosa yang amat nyata.

Dunia amnya dan Malaysia khususnya kini menghadapi tahun-tahun yang begitu kompleks dari aspek hubungan kemanusiaan. Interaksi sesama penghuni dunia kian meruncing dengan beberapa peristiwa yang menggugat keharmonian seperti propaganda Barat yang mencanangkan 'Islamo-phobia.' Peristiwa 9/11 dan rentetan serangan US atas nama anti keganasan membawa kepada ketakutan dan tiadanya toleransi antara penganut agama. $^{19}$

Hubungan antara agama yang diwarnai dengan semangat permusuhan dan sekaligus mengancam pembinaan peradaban akan berkelanjutan seandainya imej Islam yang diiktiraf sebagai ad-din

17 Anisah Musa (kakak Norhafizah Musa), dalam temu bual dengan penulis, 19 Oktober 2019.

18 "Bayan Linnas Siri Ke 22: Berita: Konsep Tabayyun dan Penerimaannya," laman sesawang Mufti Wilayah Persekutuan, dicapai 23 Okt 2019, https://muftiwp.gov.my/en/artikel/bayan-linnas/3490-bayan-linnas-siri-ke-22berita-konsep-tabayyun-dan-penerimaannya

19 Zaleha Kamaruddin dan Abdul Rashid Moten, Muslim Women Promoting Peace (Kuala Lumpur: IIUM Press, 2017), 155. 
yang berfungsi sebagai panduan dan tatacara hidup seterusnya melengkapi cara hidup umat manusia tidak segera dipulihkan secara efektif melalui pendekatan dialog. ${ }^{20}$ Dalam konteks semasa, pendakwah selebriti wanita turut menerima cabaran daripada realiti ini apabila kadang kala dakwah mereka disekat oleh pihak atasan. Dada akhbar 2018 pernah melaporkan senarai nama pendakwah termasuklah pendakwah selebriti wanita yang dihalang daripada berdakwah di TV tanpa sebarang penjelasan dan tanpa peluang membela diri. ${ }^{21}$ Bukan itu sahaja, pendakwah selebriti wanita kadang kala mengalami kesukaran untuk memasuki negara-negara tertentu yang memandang negatif kepada usaha dakwah.

Bagi Norhafizah, kadangkala, penganjur yang menjemput terpaksa membatalkan program secara mengejut apabila keluar surat dari pihak atasan dengan alasan kemasukan beliau ke sesebuah negeri tidak mendapat kelulusan. ${ }^{22}$ Misalnya, seperti apa yang pernah berlaku di Pasir Gudang, Johor untuk jemputan pada 1 November 2018. ${ }^{23}$ Menurut beliau, penolakan beliau ke majlis itu tanpa penjelasan. ${ }^{24}$

Norhafizah mengatasi cabaran ini dengan membangkitkan cadangan dalam "WhatsApp" Dewan Dakwah Negara agar melakukan sesuatu supaya hak para pendakwah terjaga. ${ }^{25}$ Setelah dibincangkan dalam kumpulan "WhatsApp" tersebut, antara faktor

${ }^{20}$ Khadijah Mohd Khambali @Hambali, "Panduan Dialog Antara Agama dalam Disiplin Ilmu Perbandingan Agama di Malaysia Menurut Konteks Fiqh alTa'ayusy," dalam Rahmah li al-A'lamin, Dakwah dalam Masyarakat Majmuk di Malaysia, ed. Zulkefli Aini, Mohamad Zulkifli Abdul Ghani \& Zainab Ismail (UKM: Pusat Kesejahteraan Insan dan Komuniti, 2018), 55.

21 "Tauliah Penceramah Agama Kini Bawah Gobind," laman sesawang ISMA, dicapai 28 Ogos 2019, https://www.ismaweb.net/2018/12/17/tauliahpenceramah-agama-kini-bawah-gobind-asyraf-wajdi/

22 Norhafizah Musa (pendakwah selebriti), dalam perbincangan di WhatsApp Dewan Dakwah Negara, 29 Oktober 2018.

23 Norhafizah Musa (pendakwah selebriti), dalam perbincangan di WhatsApp Dewan Dakwah Negara, 29 Oktober 2018.

24 Norhafizah Musa (pendakwah selebriti), dalam perbincangan di WhatsApp Dewan Dakwah Negara, 29 Oktober 2018.

25 Norhafizah Musa (pendakwah selebriti), dalam perbincangan di WhatsApp Dewan Dakwah Negara, 29 Oktober 2018. 
penyebab yang dikenal pasti ialah, ada sesetengah negeri agak ketat dalam memastikan pendakwah yang masuk ke negerinya, dengan mensyaratkan penceramah terbabit turut mempunyai tauliah daripada negeri tersebut juga.

Antara faktor penyebabnya juga ialah, kelulusan seseorang pendakwah itu mungkin dianggap tertakluk kepada Enakmen Pentadbiran Agama Islam sesebuah negeri. Antara contoh enakmen itu ialah, Enakmen Pentadbiran Agama Islam (Negeri Johor) 2003 (Enakmen 16/2003), Kaedah-kaedah Mengajar dan Memberi Syarahan Agama 1991 Jabatan Agama Islam Negeri Johor. $^{26}$

Norhafizah juga mengatakan pernah dua kali penganjur yang menjemput dirinya untuk rancangan Forum Perdana Ehwal Islam di Rancangan Televisyen Malaysia (RTM) terpaksa membatalkan jemputan atas alasan tidak dibenarkan oleh Jabatan Kemajuan Islam Malaysia (JAKIM) namun tidak diketahui atas arahan siapa kerana pembatalan diarah tanpa sebarang penjelasan. ${ }^{27}$

Selain itu, Isfadiah pula berkongsi bahawa dalam berdakwah, banyak peristiwa yang manis berbanding yang pahit dan masyarakat sering menunjukkan penerimaan yang positif. ${ }^{28}$ Namun begitu, beliau masih merasakan ketidakpastian penerimaan atau penentangan dakwah oleh pihak sekeliling terhadap isu yang diketengahkan apabila beliau berkata:

"Dahulunya, orang memandang sepi isu keibubapaan.

Proposal untuk membuat 'training' isu keibubapaan biasanya sukar diluluskan. Namun semakin lama ia semakin diterima. Bagi mengatasi ketidakpastian ini, cabaran bagi saya ialah bagaimana untuk terus menjelaskan isu ini ke tengah masyarakat dengan penyampaian yang kreatif". ${ }^{29}$

${ }^{26}$ Enakmen Pentadbiran Agama Islam sesebuah negeri. Antara contoh enakmen itu ialah, Enakmen Pentadbiran Agama Islam (Negeri Johor) 2003 (Enakmen 16/2003), Kaedah-kaedah Mengajar dan Memberi Syarahan Agama 1991 Jabatan Agama Islam Negeri Johor.

27 Norhafizah Musa (pendakwah selebriti), dalam perbincangan di WhatsApp Dewan Dakwah Negara, 14 Disember 2018.

${ }^{28}$ Norhafizah Musa (pendakwah selebriti), dalam perbincangan di WhatsApp Dewan Dakwah Negara, 14 Disember 2018.

29 Norhafizah Musa (pendakwah selebriti), dalam perbincangan di WhatsApp Dewan Dakwah Negara, 14 Disember 2018. 


\section{Kerumitan Mengurus Pelbagai Ideologi Masyarakat (Complexity)}

Cabaran hari ini pendakwah selebriti wanita berhadapan dengan pelbagai golongan dan ideologi masyarakat. Ruang lingkup kehidupan bersama keanekaan etnik, warna kulit, anutan keyakinan, budaya, pemikiran dan fahaman boleh menjadi cabaran utama untuk mewujudkan keharmonian hidup bersama (peaceful coexistence). ${ }^{30}$

Berhadapan cabaran ini, pendakwah selebriti wanita perlu teguh dengan prinsip bahawa hanya Islam agama yang diterima di sisi Allah seperti yang disebut dalam Surah Ali 'Imran, ayat 19. Oleh sebab itulah, pendakwah selebriti wanita mestilah terus mengajak kepada Islam yang digambarkan penuh keindahan agar masyarakat menjadi tertarik untuk mengamalkan cara hidup Islam dengan rela tanpa paksaan. Pendakwah selebriti wanita juga perlu menjaga pemikiran agar tidak terjerumus dalam pemikiran liberal yang menganggap semua agama adalah sama seperti yang dijelaskan oleh Mufti Wilayah Persekutuan:

"Islam adalah agama rahmat yang bersifat universal, penuh toleransi dan menerima hakikat wujudnya pelbagai agama (pluraliti) di muka bumi ini. Namun demikian, ia bukan bermakna Islam menyeru kepada kesamarataan agama seperti yang dipercayai dalam ajaran pluralisme agama. Justeru, kami menyokong penuh keputusan Muzakarah Jawatankuasa Fatwa Majlis Kebangsaan Hal Ehwal Ugama Islam Malaysia kali ke 74 pada 25 - 27 Julai 2006 berkenaan gerakan pemikiran liberal yang mengandungi fahaman-fahaman menyeleweng termasuk konsep pluralisme yang disenaraikan sebagai salah satu doktrin yang sesat lagi menyesatkan". ${ }^{31}$

Selain itu, kefahaman Islam dan implementasinya yang belum menyeluruh menyebabkan penindasan terhadap wanita masih wujud hingga kini. Bertitik tolak dari sinilah kencangnya

${ }^{30}$ Khadijah Mohd Khambali @Hambali, "Panduan Dialog Antara Agama dalam Disiplin Ilmu Perbandingan Agama di Malaysia Menurut Konteks Fiqh AlTa'ayusy," 56.

31 "Pluralisme Agama," laman sesawang Mufti Wilayah Persekutuan, dicapai 23/10/2019, https://muftiwp.gov.my/ms/artikel/tashih-al-mafahim/2999tashih-al-mafahim-8-pluraliti-agama-bukan-pluralisme-agama 
gerakan feminisme memperjuangkan hak asasi manusia (human rights), terutamanya berkenaan wanita yang menurut mereka sentiasa menjadi mangsa keganasan dan ketidakadilan sejak sekian lama, sama ada dalam lingkungan keluarga, masyarakat, mahupun dalam konteks politik dan ekonomi. ${ }^{32}$ Dalam kefahaman aliran feminisme ini, ada yang boleh diterima seperti pembelaan terhadap hak-hak wanita yang tertindas dan ada juga kefahaman yang melampaui had seperti tuntutan kebebasan orientasi seksual, identiti dan ekspresi gender. ${ }^{33}$

Di samping cabaran aliran feminisme, pendakwah selebriti wanita juga perlu berhadapan pelbagai fahaman yang cenderung ke timur. Fahaman ini mencorakkan persepsi negatif masyarakat terhadap watak dan peranan wanita. Ianya bukanlah sesuatu yang menghairankan lantaran cabaran pelbagai persepsi yang dilontarkan kepada wanita telah berlaku sejak sekian lama. AlQaradawī menulis kata pengantarnya di dalam buku Tahrīr alMar'ah fi al-Așr al-Risālah, bahawa ada juga mereka yang melihat kaum wanita lewat kaca mata hitam pekat sehingga wanita dilihat bagaikan kuman penyakit dan kejahatan di dunia. ${ }^{3}$

Manakala Muḥammad al-Ghazālī pula berkata dalam pengantar buku yang sama, bahawa kaum muslimin sudah jauh menyimpang dari tuntutan agama dalam melayani kaum wanita lantaran banyak hadis palsu atau mendekati palsu yang tersebar. Kesannya, wanita terperangkap dalam kemunduran bidang agama dan dunia sekaligus. ${ }^{35}$

Isfadiah menyatakan bahawa beliau tidak lari daripada cabaran persepsi masyarakat misalnya yang berkaitan hiasan di wajah dan gaya pakaian yang selalunya dibuat kerana meraikan kehendak penerbit $\mathrm{TV}^{36}$. Dalam ketawa sopan, beliau berkata:

32 Zulkifli Mohd Yusoff dan Aunur Rafiq, Isu-isu Gender: Perspektif Ulama alAzhar (Selangor: Intel Multimedia and Publication, 2007), 30.

33 Zulkifli Mohd Yusoff dan Aunur Rafiq, Isu-isu Gender: Perspektif Ulama alAzhar, 30.

34 'Abd Halīm Muhammad Abū Shuqqah, Tahrīr al-Mar'ah fì al-'Așr alRisālah (Indiana Universiti: Dār al-Qalam, 1990), xii.

35 'Abd Halīm Muhammad Abū Shuqqah, Taḥrīr al-Mar'ah fì al-'Așr alRisālah, xv.

36 Isfadiah Mohd Dasuki (pendakwah selebriti), dalam temubual dengan penulis, 15 Jun 2019. 
"Label 'tabarruj' yang dilontarkan oleh golongan tertentu tu biasalah. Ustazah Fatimah pun pernah kena kan? Tak mengapa selagi kita yakin, gaya dan pakaian itu masih patuh syariah." 37

Mentaliti dan fokus segelintir masyarakat yang terlalu cenderung kepada perkara cabang itu tidak merencatkan dakwah beliau bahkan beliau menghadapi cabaran itu dengan terus berpenampilan menarik, sederhana dan patuh syariah. Beliau juga memberi penjelasan yang berhikmah tentang ruang lingkup Fiqh Wanita $^{38}$. Penjelasan itu sedikit-sebanyak memberi kesan pada cara fikir masyarakat agar tidak terlalu sempit ke Timur dan tidak pula terlalu bebas ke Barat. Ketika ditanya tentang bacaan yang disukai, Isfadiah yang berkelulusan dalam bidang Psikologi ini berkata:

"Al-Quran dan al-Sunnah tetap rujukan pertama. Saya suka kepada kajian-kajian. Saya turut membaca bacaan daripada Barat. Jika ia 'inline' dengan al-Quran al-Sunnah, saya mengambilnya. Jika tidak, saya mengutamakan al-Quran dan al-Sunah. Saya juga meminati bacaan berkaitan psikologi, antropologi dan kemasyarakatan. ${ }^{39}$ ",

Inilah bekalan minda yang terus menjadi kekuatan kepada beliau di medan dakwah. Beliau juga menghadapi cabaran itu dengan bergabung dengan institusi dakwah peringkat Negara iaitu sebagai Felo Yayasan Dakwah Islamiah Malaysia (YADIM) di samping Majlis Dakwah Negara (MDN). ${ }^{40}$

\section{Kekaburan Antara Dakwah dan Profesion (Ambiguity)}

Kekaburan antara dakwah dan profesion berkait rapat dengan keikhlasan pendakwah yang dipertikaikan. Pada masa kini, menurut Siti Rugayah Tibek, kurangnya pendakwah yang benar-

37 Isfadiah Mohd Dasuki (pendakwah selebriti), dalam temubual dengan penulis, 15 Jun 2019.

38 "Ustazah Isfadiah Cinta Ilmu TV ALHIJRAH", laman sesawang YouTube, dicapai 29 Ogos 2019, https://www.youtube.com/watch?v=XwkpHAT_kNI

39 Isfadiah Mohd Dasuki (pendakwah selebriti), dalam temubual dengan penulis, 3 Ogos 2018.

40 Isfadiah Mohd Dasuki (pendakwah selebriti), dalam temubual dengan penulis, 3 Ogos 2018. 
benar sanggup berkorban tenaga dan harta demi dakwah. ${ }^{41}$ Kenyataan ini diperkukuhkan lagi dalam kertas kerja bertajuk Wasatiyyah, Manhaj Dakwah Masa Kini yang mana antara isu yang diangkat ialah keikhlasan dan kejujuran para pendakwah. Menurut kertas kerja tersebut, sifat ini akan terus mencabar para pendakwah, kerana mereka terikut-ikut dengan ahli-ahli korporat yang memperkirakan setiap minit dan tugas yang mereka lakukan. Hakikatnya, dunia dakwah amat berbeza dengan kegiatan dan tugas ahli korporat dan golongan profesionalisme yang lain. Justeru, para rasul diamanahkan oleh Allah SWT agar menjalankan kewajipan mereka dengan ikhlas dan sabar atas segala ujian yang sering kali dihadapi oleh mereka. ${ }^{42}$

Cabaran ini tidak menyangkut isu pendakwah yang mengambil bayaran tetapi menyangkut isu pendakwah yang meletakkan harga ceramahnya terlalu tinggi sehingga membebankan penganjur. Pendakwah bukannya tidak boleh menerima apa-apa bayaran daripada usaha dakwahnya sedangkan pendakwah juga manusia yang mempunyai perut dan tanggungan. Namun, kedua-dua pihak, pendakwah dan penganjur biarlah berpatutan. Zulkifli al-Bakri berkata:

"Perselisihan yang berlaku akibat daripada kekaburan maklumat atau berita yang diperoleh menjadikan seluruh masyarakat hidup dalam keadaan sentiasa syak wasangka terhadap sesama sendiri." 43

Beliau juga mengingatkan bahawa berita atau sebarang maklumat yang diterima seharusnya diteliti dan dipastikan dahulu kebenarannya dan ketepatan informasi bagi mengelakkan sebarang agenda atau perkara yang tidak baik berlaku seperti menfitnah, menipu dan memburukkan seseorang yang lain berlandaskan hawa nafsu dan sifat kebencian seperti saranan Allah SWT dalam alHujurat, ayat 6 .

${ }^{41}$ Siti Rugayah Tibek, Wanita, Dakwah dan Media, Wanita Islam Isu-isu dan Pemerkasaan Hak, 53.

${ }^{42}$ Siti Rugayah Tibek, Wanita, Dakwah dan Media, Wanita Islam Isu-isu dan Pemerkasaan Hak, 53.

43 "Bayan Linnas Siri Ke 22: Berita: Konsep Tabayyun dan Penerimaannya," laman sesawang Mufti Wilayah Persekutuan, dicapai 23 Okt 2019, https://muftiwp.gov.my/en/artikel/bayan-linnas/3490-bayan-linnas-siri-ke-22berita-konsep-tabayyun-dan-penerimaannya. 
Tidak dapat dinafikan, keikhlasan pendakwah selebriti wanita kadang kala dipertikaikan oleh masyarakat ${ }^{44}$. Yūsuf al-Qarḍawī menggambarkan orang yang tidak ikhlas sebagai:

"Orang yang memuja dunia dan seronok melihat dada akhbar yang penuh dengan tulisan yang memuja-muja kehebatan dirinya, dasarnya cuma 'Aku,' sedangkan orang lain tidak dipedulikan." 45

Walau bagaimanapun, sikap konsisten pendakwah selebriti wanita dalam pengurusan masyarakat mencerminkan keikhlasan. Berbekalkan keikhlasan, pengurusan masyarakat bermatlamatkan Allah SWT dan tidak mudah terhalang oleh apa jua cabaran seperti keikhlasan Khalid al-Walid yang tetap memilih untuk berjihad tidak kira sama ada sebagai panglima perang atau sebagai tentera biasa." 46

Dalam menghadapi keempat-empat cabaran pengurusan masyarakat tersebut, pendakwah selebriti wanita perlu menambah ilmu yang boleh menghadapi kerenah golongan $\operatorname{sasaran}^{47}$. Pendakwah selebriti wanita seharusnya perlu kepada ilmu sampingan untuk memahami tingkah laku sasaran seperti ilmu psikologi, antropologi dan kemasyarakatan serta ilmu alat untuk berdakwah seperti bahasa dan media. ${ }^{48}$

Kajian mendapati Norhafizah mempunyai pandangan yang jelas tentang perbezaan antara dakwah dan profesion. Beliau berdakwah bukan sekadar mencari keuntungan duniawi sematamata. Buktinya, walaupun beliau mempunyai pangkat dan gelaran 'Datuk Dr. Ustazah,' dan masih menjadi rebutan penganjur seandainya beliau meletakkan harga yang tinggi untuk

44 Abdullah Muhammad Zin, "Wasatiyyah Sebagai Manhaj Dakwah Masa Kini”" (Kertas Kerja, Multaqa Pendakwah Negara dan Serantau, Institut Latihan Dewan Bandaraya Kuala Lumpur, 3 November 2015).

45 Yusuf al-Qaradhawi, Ikhlas dalam Ibadah dan Perjuangan, terj. Adul Ghani Samsudin dan Pauzi Awang (Shah Alam: Persatuan Ulama Malaysia, 2000), 7.

${ }^{46}$ Cahyadi Takariawan, Tegar di Jalan Dakwah, 136.

47 Siti Rugayah Tibek, Wanita, Dakwah dan Media, Wanita Islam Isu-isu dan Pemerkasaan Hak, 53.

48 Siti Rugayah Tibek, Wanita, Dakwah dan Media, Wanita Islam Isu-isu dan Pemerkasaan Hak, 53. 
ceramahnya, namun beliau merendahkan hati dengan mengambil kira kemampuan penganjur. Beliau berkata:

"Kak Cik tidak pernah menetapkan bayaran tertentu sebaliknya pihak penganjur yang meletakkan pertimbangan yang wajar dan sekiranya Kak Cik dapat penuhi, Kak Cik akan penuhi jemputan tersebut. ${ }^{49}$,

Puteri sulung beliau mendedahkan:

"Ummi lebih banyak menerima respons positif dan pujian berbanding tentangan". 50

Beliau berkata lagi:

"Respons positif ini juga suatu cabaran agar lebih berhati-hati menjaga amanah agama ini. Memang tidak dinafikan, walaupun di telinga Kak Long sangat jarang mendengar respons negatif terhadap ummi, namun dalam kehidupan ini, masih terdapat orang yang suka dan orang yang tidak suka kepada ummi, ianya lumrah perkara biasa. Apa yang pasti, hal itu langsung tidak memberi kesanpun kepada kehidupan ummi.,, 51

Norhafizah melalui cabaran kekaburan masyarakat antara masyhur dan mengejar kemasyhuran apabila beliau berkata,

"Menjadi orang yang dikenali sebenarnya banyak cabaran dan tekanan. Pertamanya ia membuatkan orang lain membentuk persepsi tentang dirinya, terutamanya orang terdekat. Orang melihat seolah-olah seronok menjadi orang terkenal, padahal Allah yang Maha Tahu. Ia kadang kala menjadi sesuatu yang merimaskan. Ada ketika kita hanya mahu dilayan seperti orang biasa." 52

Dalam menjalani kehidupan harian, di mana-mana sahaja, beliau mengakui, masyarakat yang mengenali beliau pasti akan mahu bersalam, menyapa, bergambar, berkongsi dan bertanya

49 Norhafizah Musa (pendakwah selebriti), dalam temubual online dengan penulis, 20 Mei 2019.

50 Nur Nadhratul Naemah binti Mohd Azhar (anak sulung pendakwah selebriti Norhafizah Musa), dalam temubual dengan penulis, 12 April 2019.

51 Nur Nadhratul Naemah binti Mohd Azhar (anak sulung pendakwah selebriti Norhafizah Musa), dalam temubual dengan penulis, 12 April 2019.

52 Norhafizah Musa (pendakwah selebriti), dalam temubual dengan penulis, 15 Oktober 2018. 
permasalahan mereka ${ }^{53}$. Bagi sesetengah pihak, kemasyhuran itu terus dipersepsikan dengan ketidakikhlasan berdakwah, bahkan keikhlasan pendakwah masa kini dipertikaikan seperti mana yang disebut oleh Abdullah Muhammad Zin dalam kertas kerjanya ${ }^{54}$. Walhal, kemasyhuran itu datang sendiri dengan izin Allah seperti mana datangnya kemasyhuran kepada Rasulullah SAW dan para sahabat tidaklah tercela seperti yang disebut oleh al-Qarḍāwī. ${ }^{55}$

Pendakwah selebriti ini bukanlah mengejar atau menggilai kemasyhuran itu apabila beliau mengakui ada kerimasan di sudut hatinya terhadap ujian kemasyhuran sehingga sesekali beliau kadangkala mengelakkan suasana dikerumuni ramai. ${ }^{56}$ Buktinya, beliau kadang kala berstrategi memakai purdah apabila keluar membeli barang-barang di pasar agar tidak dikenali. ${ }^{57}$ Bahkan, menurut puteri sulung beliau:

"Ummi pernah dinasihatkan oleh doktor untuk sengaja berehat lebih lama di hospital bagi mengurangkan kesibukan dikelilingi masyarakat setiap hari. ${ }^{58}$ Kesibukan beliau melayani tuntutan masyarakat sampai tahap paginya ummi berkhidmat di negara lain, petangnya pula apabila dihubungi ummi berada di negara lain pula".

Ia tidak menghalang beliau untuk terus melangkah menjadi seorang wanita berpendidikan tinggi kerana konsistensi terhadap ilmu adalah cara beliau menjaga keikhlasan. ${ }^{60}$ Beliau telah menyambung pengajian dalam bidang Psikospritual dan Akidah sehingga ke peringkat tertinggi iaitu $\mathrm{PhD}$. Beliau pernah menjawat

53 Ibid.

54 Abdullah Muhammad Zin, "Wasatiyyah Sebagai Manhaj Dakwah Masa Kini," t.h.

55 Yusuf al-Qaradhawi, Ikhlas dalam Ibadah dan Perjuangan, terj. Adul Ghani Samsudin dan Pauzi Awang, 121.

56 Norhafizah Musa (pendakwah selebriti), dalam temubual dengan penulis, 15 Oktober 2018.

57 Norhafizah Musa (pendakwah selebriti), dalam temubual dengan penulis, 15 Oktober 2018.

58 Nur Nadhratul Naemah binti Mohd Azhar (anak sulung pendakwah selebriti Norhafizah Musa), dalam temubual dengan penulis, 12 April 2019.

59 Nur Nadhratul Naemah binti Mohd Azhar (anak sulung pendakwah selebriti Norhafizah Musa), dalam temubual dengan penulis, 12 April 2019.

${ }^{60}$ Nur Nadhratul Naemah binti Mohd Azhar (anak sulung pendakwah selebriti Norhafizah Musa), dalam temubual dengan penulis, 12 April 2019. 
jawatan pensyarah di Universiti Teknologi Malaysia (UTM) Kampus Antarabangsa KL. Beliau juga aktif menguruskan sebuah pusat pendidikan tahfiz di Gombak iaitu Madinatul Huffaz. Beliau menggunakan 3 jam sehari untuk menelaah buku-buku mengikut kelapangan masa. ${ }^{61}$

Beliau menulis:

"Faktor utama keyakinan adalah kedudukan ilmu yang ada pada diri seseorang. Buktinya, seorang wanita yang cantik, tetapi sangat cetek akal dan ilmunya akan menurunkan daya tarikan orang lain terhadap dirinya., 62

Puteri sulung beliau berkata:

"Ummi suka mendengar pengisian agama daripada youtube sebelum tidur untuk menambah ilmu. Ummi juga kerap melakukan pengembaraan sambil menziarahi ulama misalnya di Bandung untuk meminta nasihat. Ummi juga biasa meminta nasihat daripada orang sekeliling seperti kakakkakak, anak-anak, ustaz dan ustazah sekeliling."

Sedikit berbeza dengan Norhafizah, Isfadiah menjelaskan bahawa, hidup beliau lebih dilimpahi pujian dan respons positif dalam masyarakat dan hampir tidak pernah diberi label tertentu oleh pihak atasan. ${ }^{64}$ Suami beliau juga mengesahkan hal ini dan berkata bahawa what you give, you get back. ${ }^{65}$ Ia boleh menjadi suatu cabaran yang membenihkan penyakit ujub dan riyak dalam hati. Namun, beliau tidak memilih untuk berhenti berdakwah kerana menurut perspektif Islam, meninggalkan kebaikan lantaran takut riyak juga adalah riyak. ${ }^{66}$ Sebaliknya beliau mengatasi cabaran itu dengan memastikan dakwahnya tidak berhenti kerana perbuatan yang dibuat bukan kerana Allah akan tercantas dan

61 Majalah Usrati, isu 2, 2013, Raudhah Global Resources, 9.

62 Norhafizah Musa, Cantik Wanita Seindah Mutiara (Batu Caves: PTS, 2017), 11.

63 Nur Nadhratul Naemah binti Mohd Azhar (anak sulung pendakwah selebriti Norhafizah Musa), dalam temubual dengan penulis, 12 April 2019.

64 Isfadiah Mohd Dasuki (pendakwah selebriti), dalam temubual dengan penulis, 15 Jun 2019.

65 Muhidin Mokter, dalam perkongsian di Masjid, al-Raudhah, Syeksyen U10, Shah Alam, 20 Julai 2019.

66 Yusuf al-Qaradhawi, Ikhlas dalam Ibadah dan Perjuangan, 121. 
terputus. $^{67}$ Ia selaras dengan pendapat al-Qaradāwī bahawa perbuatan yang dibuat kerana Allah SWT akan berkekalan dan berkesinambungan, manakala perbuatan yang dibuat bukan kerana Allah SWT akan tercantas dan terputus. ${ }^{68}$ Beliau juga mengatasinya dengan memperkuatkan tarbiah ruh dalam pengurusan diri. ${ }^{69}$

Dalam perkongsian ilmu beliau di Multaqa Pendakwah Negara dan Serantau $2015^{70}$, beliau ditanya berkenaan dakwah dan profesion. Beliau menegaskan bahawa:

"Kerjaya menjadi doktor, peguam dan pendakwah perlu melalui proses yang sama iaitu menghabiskan tempoh masa sekurang-kurangnya 3 ke 4 tahun belajar di universiti. Selepas bergraduasi, hendak berjumpa doktor misalnya ada bayaran buka pintu (konsultasi), kemudian ada lagi bayaran perkhidmatan. Begitu juga peguam. Namun untuk mendapatkan khidmat pendakwah, masyarakat sering kali mempertikaikan apabila diletakkan bayaran."

Beliau menghadapi cabaran ketidakjelasan antara dakwah dan profesion ini dengan memberi penerangan yang baik bahawa pendakwah juga memiliki keperluan hidup seperti ahli profesional yang lain. ${ }^{71}$

Berdasarkan kepada analisis terhadap temu bual mendalam, kajian mendapati cabaran pendakwah selebriti wanita dalam pengurusan masyarakat dan cara mengatasinya boleh diringkaskan sebagaimana jadual di bawah:

67 Yusuf al-Qaradhawi, Ikhlas dalam Ibadah dan Perjuangan, 185.

68 Yusuf al-Qaradhawi, Ikhlas dalam Ibadah dan Perjuangan, 185.

69 Isfadiah Mohd Dasuki (pendakwah selebriti), dalam temubual dengan penulis, 15 Jun 2019.

70 Isfadiah Mohd Dasuki, dalam perkongsian di Multaqa Pendakwah Negara dan Serantau, Dewan Perdana Mestika, Institut Latihan Dewan Bandaraya Kuala Lumpur, bertarikh 3 November 2015.

71 Isfadiah Mohd Dasuki, dalam perkongsian di Multaqa Pendakwah Negara dan Serantau, Dewan Perdana Mestika, Institut Latihan Dewan Bandaraya Kuala Lumpur, bertarikh 3 November 2015. 


\begin{tabular}{|c|c|c|}
\hline & Cabaran & Cara mengatasi \\
\hline \multirow{3}{*}{ 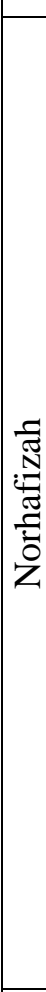 } & $\begin{array}{lll}\begin{array}{l}\text { Perubahan } \\
\text { globalisasi. }\end{array} & & \\
\text { O Tawaran } & \text { media } & \text { yang } \\
\text { syubhah. } & & \\
\end{array}$ & $\begin{array}{l}\text { Selalu meminta panduan } \\
\text { daripada keluarga dan para } \\
\text { alim ulama. }\end{array}$ \\
\hline & $\begin{array}{l}\text { Ketidakpastian penerimaan } \\
\text { atau penentangan dakwah } \\
\text { oleh pihak sekeliling. } \\
\text { o Pembatalan mengejut } \\
\text { ceramah oleh pihak atasan } \\
\text { tanpa penjelasan. }\end{array}$ & \begin{tabular}{lrr} 
Membangkitkan & cadangan \\
dalam & WhatsApp & Dewan \\
Dakwah & Negara & agar \\
melakukan & sesuatu & supaya \\
\multicolumn{4}{l}{ hak para pendakwah terjaga. }
\end{tabular} \\
\hline & $\begin{array}{l}\text { Kekaburan antara dakwah } \\
\text { dan profesion. } \\
\text { o Populariti dipersepsikan } \\
\text { masyarakat sebagai tidak } \\
\text { ikhlas. }\end{array}$ & $\begin{array}{l}\text { O Mengambil kira } \\
\text { kemampuan penganjur } \\
\text { dalam soal bayaran. } \\
\text { o Kadangkala menjauhi } \\
\text { populariti dengan memakai } \\
\text { purdah. } \\
\text { o Terus melangkah menjadi } \\
\text { seorang } \\
\text { berpendidikan tinggi } \\
\text { kerana konsistensi terhadap } \\
\text { ilmu adalah cara beliau } \\
\text { menjaga keikhlasan. }\end{array}$ \\
\hline & $\begin{array}{l}\text { Kekaburan antara dakwah } \\
\text { dan profesion. } \\
\text { o Dilimpahi pujian yang } \\
\text { menguji keikhlasan. }\end{array}$ & $\begin{array}{l}\text { O Memastikan dakwah tidak } \\
\text { terhenti. } \\
\text { o Memberi penerangan yang } \\
\text { baik bahawa pendakwah } \\
\text { juga memiliki keperluan } \\
\text { hidup seperti ahli } \\
\text { profesional yang lain. }\end{array}$ \\
\hline & $\begin{array}{l}\text { Kerumitan mengurus } \\
\text { pelbagai persepsi masyarakat. } \\
\text { o Persepsi masyarakat } \\
\text { misalnya yang berkaitan } \\
\text { hiasan di wajah dan gaya } \\
\text { pakaian yang selalunya } \\
\text { dibuat kerana meraikan } \\
\text { kehendak penerbit program } \\
\text { TV. }\end{array}$ & $\begin{array}{l}\text { O Memberi penjelasan yang } \\
\text { berhikmah tentang ruang } \\
\text { lingkup Fiqh Wanita. }\end{array}$ \\
\hline
\end{tabular}




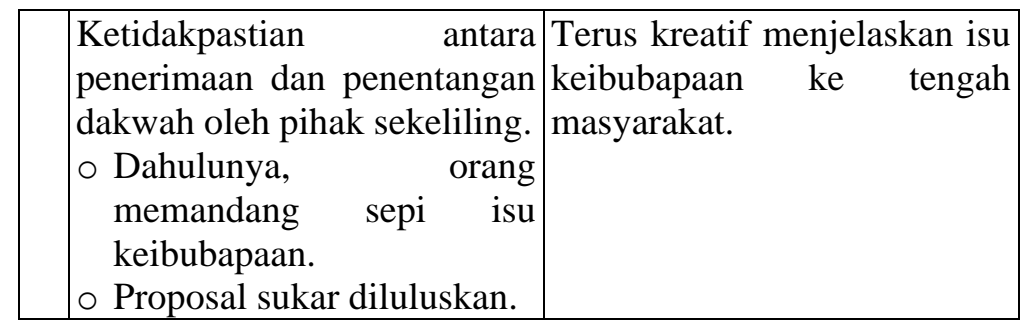

Begitulah cabaran pengurusan masyarakat yang dihadapi oleh Norhafizah dan Isfadiah yang kebanyakannya datang dari faktor luaran. Mereka terus melangkah memajukan diri meski apapun cabaran yang menghimpit.

\section{Penutup}

Lumrah pendakwah pasti melalui cabaran seperti mana yang dikisahkan dalam al-Quran. Begitu juga pendakwah selebriti wanita di Malaysia. Dalam era globalisasi ini, antara cabaran yang dihadapi oleh pendakwah selebriti wanita ialah perubahan mendadak dunia globalisasi terutamanya yang melibatkan media, kerumitan mengurus pelbagai ideologi masyarakat, ketidakpastian penerimaan atau penentangan dakwah dan kekaburan antara dakwah dan profesion. Walaupun dihimpit cabaran-cabaran ini, usaha dakwah mereka terus konsisten dan memberi impak sehingga diikuti oleh ratusan ribu pengikut di media sosial. Kekuatan ilmu yang sentiasa dimajukan boleh mengatasi pelbagai cabaran. Bukan sahaja ilmu asas tetapi juga ilmu sampingan seperti ilmu psikologi, antropologi dan kemasyarakatan. Ilmu alat seperti bahasa dan media yang menjadi perantara penyampaian dakwah juga membantu mereka mengatasi cabaran kontemporari. Kajian ini juga membawa kepada dua implikasi. Pertamanya, keperluan mendengar dan memahami suara pendakwah selebriti wanita bagi memperkasakan usaha dakwah mereka. Keduanya, keperluan menyatukan pendakwah selebriti wanita dalam institusi dakwah peringkat negara agar suara mereka lebih didengari dan sebagai suatu usaha mencari penyelesaian kepada pelbagai bentuk cabaran dan masalah. 


\section{Rujukan}

"Bayan Linnas Siri Ke 22: Berita: Konsep Tabayyun dan Penerimaannya," laman sesawang Mufti Wilayah Persekutuan, dicapai 23 Okt 2019, https://muftiwp.gov.my/en/artikel/bayanlinnas/3490-bayan-linnas-siri-ke-22-berita-konsep-tabayyundan-penerimaannya

"Pluralisme Agama," laman sesawang Mufti Wilayah Persekutuan, dicapai 23/10/2019, https://muftiwp.gov.my/ms/artikel/tashihal-mafahim/2999-tashih-al-mafahim-8-pluraliti-agama-bukanpluralisme-agama

"Selebriti", laman sesawang Dewan Bahasa dan Pustaka, dicapai 17 April 2018 , http://prpm.dbp.gov.my/Cari1?keyword=selebriti

"Tauliah Penceramah Agama Kini Bawah Gobind," laman sesawang ISMA, dicapai 28 Ogos 2019, https://www.ismaweb.net/2018/12/17/tauliah-penceramahagama-kini-bawah-gobind-asyraf-wajdi/

"Ustazah Isfadiah Cinta Ilmu TV ALHIJRAH", laman sesawang YouTube, dicapai 29 Ogos 2019, https://www.youtube.com/watch?v=XwkpHAT_kNI

Abdullah Muhammad Zin. "Wasatiyyah Sebagai Manhaj Dakwah Masa Kini." Kertas Kerja, Multaqa Pendakwah Negara dan Serantau, Institut Latihan Dewan Bandaraya Kuala Lumpur, 3 November 2015.

Abū Shuqqah, 'Abd Halīm Muḥammad. Taḥīr al-Mar'ah fì al'Așr al-Risālah. Indiana Universiti: Dār al-Qalam, 1990.

Cahyadi Takariawan, Tegar di Jalan Dakwah (Solo: PT Era Adicitra Intermedia, 2010), 99.

Khadijah Mohd Khambali@Hambali. "Panduan Dialog Antara Agama dalam Disiplin Ilmu Perbandingan Agama di Malaysia Menurut Konteks Fiqh al-Ta'ayusy," dalam Rahmah li alA'lamin, Dakwah dalam Masyarakat Majmuk di Malaysia, ed. Zulkefli Aini, Mohamad Zulkifli Abdul Ghani \& Zainab Ismail. UKM: Pusat Kesejahteraan Insan dan Komuniti, 2018.

Mohd Safar Hasim dan Zulkiple Abd. Ghani. Komunikasi dan Media dari Perspektif Islam: Konsep dan Amalan. Selangor: Penerbit Universiti Kebangsaan Malaysia, 2015.

Norhafizah Musa. Cantik Wanita Seindah Mutiara. Batu Caves: PTS, 2017. 
Siti Rugayah Tibek. Wanita, Dakwah dan Media, Wanita Islam Isu-isu dan Pemerkasaan Hak. Shah Alam: Persatuan Ulama Malaysia, 2011.

Yusuf al-Qaradhawi. Ikhlas dalam Ibadah dan Perjuangan, terj. Adul Ghani Samsudin dan Pauzi Awang. Shah Alam: Persatuan Ulama Malaysia, 2000.

Zaleha Kamaruddin dan Abdul Rashid Moten. Muslim Women Promoting Peace. Kuala Lumpur: IIUM Press, 2017.

Zulkifli Mohd Yusoff dan Aunur Rafiq. Isu-isu Gender: Perspektif Ulama al-Azhar. elangor: Intel Multimedia and Publication, 2007. 